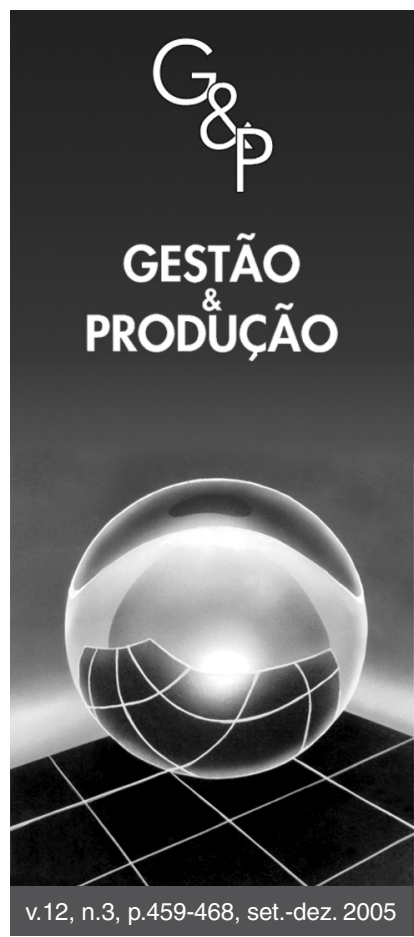

\title{
CRIAÇÃO DE VALOR E ESTRATÉGIA DE OPERAÇÕES: UM ESTUDO DO SETOR QUÍMICO E PETROQUÍMICO BRASILEIRO
}

\author{
Ivan Ricardo Gartner \\ Programa de Pós-Graduação em Administração, \\ Universidade Metodista de São Paulo, \\ Rua do Sacramento, 230, Bl. Capa, Rudge Ramos, \\ CEP 09640-000, São Bernardo do Campo, SP, Brasil, \\ e-mail: irgartner@ hotmail.com
}

Fabio Gallo Garcia

Departamento de Contabilidade, Finanças e Controle, Escola de Administração de Empresas de São Paulo, Fundação Getúlio Vargas, Av. 9 de Julho, 2029, $10^{\circ}$ andar, Bela Vista, CEP 01313-902, São Paulo, SP, Brasil, e-mail: fgallo@fgvsp.br

Recebido em 04/7/2005

Aceito em 26/10/2005

Resumo

Este artigo trata da integração da estratégia de operações às finanças, ao evidenciar a necessidade do gestor de operações de planejar uma estratégia voltada à criação de valor na companhia. O trabalho apresenta uma metodologia para o cálculo do valor econômico adicionado das empresas químicas e petroquímicas brasileiras para os anos de 2001 e 2002, período de profundas transformações no perfil competitivo do setor. Os resultados de 2002 validaram a hipótese central do trabalho e forneceram um instrumento de simulação para identificar o limiar da responsabilidade do gestor de operações com a criação de valor em uma organização.

Palavras-chave: estratégias de operações, criação de valor empresarial, setor químico e petroquímico brasileiro, regressão logística, simulação do valor empresarial.

\section{Introdução}

A preocupação com a criação de valor nas companhias tem tomado vulto nas últimas décadas, especialmente após a acentuação da luta competitiva ocasionada pelo atual fenômeno da globalização. No mundo integrado pela rede mundial de computadores e pelas demais novidades e facilidades das telecomunicações, os processos de negócios podem, num piscar de olhos ou por um clique no teclado, deslocar-se para o ambiente que oferecer maiores níveis de rentabilidade aos seus proprietários, atendendo às premissas do custo de oportunidade do capital.

Esse cenário competitivo induz os gestores a realçarem, aos proprietários e investidores de suas companhias, que sua estratégia de operações cria valor, ao invés de destruir. No caso da empresa criar valor, o gestor precisa apresentar aos seus superiores o planejamento de estratégia que vise sua sustentabilidade e aumento a longo prazo. Em situações em que a empresa estiver destruindo valor, o gestor deverá apresentar estratégia para a recomposição desse valor a curto e médio prazo.
Essas estratégias têm encontrado nos sistemas de avaliação multidimensional, do tipo Balanced Scorecard (Kaplan e Norton, 1996), a oportunidade de união de seus objetivos com as ações necessárias para alcançá-los nas perspectivas: Financeira, de Clientes, de Processos Internos, de Aprendizado e Crescimento. Por essa abordagem, todas as perspectivas devem ser sistematizadas por meio de uma cadeia de relações de causas e efeitos, que culminam com seus impactos na criação do valor da empresa.

No entanto, a medida da criação ou destruição de valor é, eminentemente, uma medida monetária, que diz respeito a uma das últimas linhas do demonstrativo de resultados da companhia, a qual concentra a maior atenção dos proprietários, acionistas, investidores e financiadores. Embora seja uma medida monetária, a utilização e manuseio da informação sobre a criação e destruição de valor não é mais privilégio dos gestores financeiros. Também os gestores de operações devem estar envolvidos direta- 
mente com o acompanhamento e monitoramento desses valores que traduzem a criação de valor na companhia.

A medida monetária da criação de valor de uma organização resulta da combinação do desempenho gerencial com sua estrutura financeira, situação tributária e quantidade de ativos não-operacionais, tais como as aplicações financeiras. Como isso evidencia que a criação de valor é condicionada por outros fatores além do desempenho operacional, resta saber quais são os limites de responsabilidade que devem ser atribuídos ao gestor de operações com relação ao valor criado ou destruído na organização.

Este estudo tem como objetivo enfocar a influência do desempenho operacional na criação de valor nas organizações. Para tanto, o objeto empírico escolhido para a aplicação foi o setor químico e petroquímico brasileiro, que está em fase de transição para um novo modelo de gestão de operações, especialmente devido à onda de fusões e aquisições ocorridas neste início do século XXI. Essa complexa dinâmica organizacional apresenta um cenário propício à produção de conhecimento sobre estratégia de operações associada à criação de valor.

A validação deste estudo prevê a comprovação da hipótese central de que os índices econômico-financeiros operacionais, conjugados com indicadores de produtividade de ativos e endividamento, explicam a criação ou destruição de valor no setor industrial analisado.

Este trabalho está estruturado em cinco partes. Na primeira parte, tem-se a consideração introdutória do trabalho, o que inclui a delimitação do tema e problemática, bem como o estabelecimento do objetivo geral e da hipótese central. Na segunda parte, encontra-se uma breve revisão do conceito de criação de valor nas operações. A terceira parte contempla a metodologia de cálculo do valor econômico criado, o universo pesquisado e as amostras consideradas. Na parte quatro, é feita uma análise dos resultados da aplicação e validada a hipótese central. A quinta parte apresenta as conclusões do estudo.

\section{Criação de valor na estratégia de operações}

A criação de valor é o objetivo geral a ser perseguido pelas organizações por meio das estratégias de suas diversas áreas funcionais, das quais se destaca a área de operações, em função do alcance de suas atividades no âmbito organizacional.

O alcance da estratégia de operações é realçado por Lowson (2001), que afirma que ela envolve a maioria das decisões sobre: i) o foco das competências, potencialidades e processos; ii) recursos; e iii) atividades táticas primordiais, que são necessárias em qualquer rede de suprimentos, de acordo com a criação e a entrega de produtos ou serviços e o valor desejado pelo cliente. O papel estratégico envolve a junção destes três blocos em uma ou mais arquiteturas estratégicas.

As escolhas ou decisões envolvidas são menos concernentes com o dia-a-dia dos indivíduos, isto é, com as atividades táticas, e mais relacionadas ao sistema de transformações como um todo, que é parte dos recursos, competências e potencialidades necessárias à organização. Estas escolhas também representam mudanças mais amplas no ambiente competitivo no qual a empresa está envolvida. O padrão dessas decisões tende a ser de médio e longo prazo, para que possa refletir os potenciais e competências principais da organização, bem como o uso dos recursos e tecnologias para sustentar a vantagem competitiva em seu segmento de atuação (Lowson, 2002).

A sustentação da vantagem competitiva por meio da estratégia de operações é abordada por Porter (1996), quando ele sugere que a criação do valor econômico verdadeiro, isto é, o hiato entre o preço e o custo do produto, será o fundamento para sua sobrevivência ou falência. A vantagem competitiva sustentável somente pode ser encontrada ao se operar um custo mais baixo ou ao se atribuir um preço-prêmio pela diferenciação, ou em função de ambos, o que pode ser obtido da seguinte forma:

- Efetividade operacional: fazer as mesmas coisas que seus competidores, mas fazendo-as melhor; $\mathrm{e}$

- Posição estratégica: fazer coisas diferentes daquelas feitas por seus competidores, de modo que se entreguem aos clientes produtos com um tipo de valor único, exclusivo.

Devido à amplitude do alcance da estratégia de operações, verifica-se a necessidade de se estabelecerem critérios e medidas para monitorar seu desempenho. Para Ahmed e Montagno (1996), o alcance da estratégia de operações deve mensurar seu impacto nos resultados globais da organização, que podem ser sintetizados em quatro grupos de fatores de desempenho:

- Mercado:

- Participação no mercado; e

- Volume de vendas.

- Produto:

- Qualidade do produto;

- Introdução de melhorias e novos produtos;

- Produtividade; e

- Habilidade de melhorar.

- Econômicos:

- Resultados anuais;

- Lucratividade; e

- Retorno sobre o investimento.

- Empregados:

- Melhoria na capacitação dos empregados; e

- Flexibilidade dos empregados. 
Embora esses fatores de desempenho sejam multidimensionais, os proprietários e investidores (shareholders) concentram suas atenções na rentabilidade da empresa analisada, sem se preocuparem especificamente com o alcance da estratégia de operações, mas com a estratégia que cria riqueza. Nesse ponto, considera-se que uma empresa é viável, quando apresentar uma taxa de rentabilidade maior do que a taxa de mínimo rendimento que é proporcionada por um investimento alternativo, em condições de risco semelhantes. Esse é o princípio do custo de oportunidade do capital, que fundamenta a teoria dos investimentos.

A rentabilidade confere confiança aos investidores, resultando na valorização das ações ou quotas da empresa. Com isso, a empresa aumenta a atratividade por capitais para os investimentos, que subsidiarão suas estratégias competitivas voltadas a garantir sua sobrevivência e sustentabilidade no mercado. Portanto, a lucratividade não é somente um resultado mas também uma fonte de saúde competitiva e de riqueza empresarial.

Caso a empresa não proporcione taxas de rentabilidade favoráveis aos investidores, estes poderão transferir seus fundos para outras alternativas mais rentáveis, o que comprometeria o financiamento e a própria sobrevivência das atividades empresariais. Por esta perspectiva, os shareholders acreditam que o sucesso de uma empresa pode ser medido por meio de instrumentos como: preço da ação, valor dos dividendos e lucro econômico.

O lucro econômico, que é um conceito mais refinado e complexo do que o apresentado por Porter (1996) anteriormente, é uma abordagem proposta originalmente pelo economista Alfred Marshall (1890), que defendia que o custo de oportunidade do capital deveria ser considerado nos cálculos dos lucros empresariais. Como a contabilidade tradicional não considerava essa premissa, Copeland et al. (1995) desenvolveram uma metodologia cuja principal contribuição foi incorporar o custo do capital próprio na estrutura de cálculo do lucro empresarial, o que tem auxiliado as empresas a monitorar o alcance de seu objetivo básico de maximizar a riqueza dos proprietários e investidores através da criação de valor econômico. A metodologia desenvolvida estabelece que o lucro econômico é a diferença entre o retorno sobre os investimentos e o custo médio ponderado de capital. Esse cálculo pode ser operacionalizado pela equação:

$$
\mathrm{LE}=\mathrm{CI} \times(R O I C-C M P C)
$$

onde CI é o capital investido, que se refere ao valor dos investimentos operacionais, como capital de giro e ativos fixos, e não-operacionais; LE é o lucro econômico; ROIC é a taxa de retorno sobre os investimentos e CMPC é a taxa do custo médio ponderado de capital, que considera a estrutura de capitais da companhia.
Uma forma de cálculo do lucro econômico mais adequada aos objetivos deste trabalho, é a que considera o resultado operacional da companhia, assim formulada:

$$
\mathrm{LE}=\mathrm{NOPLAT}-(C I \times C M P C)
$$

onde NOPLAT (Net Operating Profit Less Adjusted Taxes) é o lucro operacional líquido menos impostos ajustados.

O lucro econômico (LE) apresenta uma medida de desempenho que contabiliza adequadamente as possibilidades de criação ou destruição do valor empresarial. A empresa estará criando valor quando o LE for positivo e estará destruindo valor quando o LE for negativo.

O incremento no valor ocorrerá quando as estratégias de operações forem alinhadas às demais estratégias empresariais, visando:

- Aumentar o retorno líquido sobre os ativos em função de ações de maximização da receita e minimização dos custos; e

- Implementar os investimentos cujo retorno líquido sobre os ativos é superior ao custo médio ponderado de capital.

Portanto, verifica-se que essas formas de se incrementar o valor de uma organização transcendem os resultados da estratégia de operações da organização, concentrando-se nos resultados econômico-financeiros agregados. Conseqüentemente, é necessário estabelecer os limites de atuação e de responsabilidades da área de operações no processo, a fim de que se possam estabelecer os limiares de desempenho sob os quais ela será avaliada.

\section{Aspectos metodológicos}

\subsection{Origem dos dados e caracterização da amostra}

Os dados pesquisados são secundários e foram obtidos do Balanço das 500 Maiores Empresas Brasileiras de Sociedade Anônima (FGV, 2005). Dessa fonte de dados, foram selecionadas todas as empresas do setor químico e petroquímico que figuravam nos balanços de 2001 e 2002, tendo sido excluídas aquelas que foram listadas apenas em um dos dois anos citados, visando aumentar a estabilidade e coerência dos resultados da análise. Dessa amostra de empresas, que é do tipo não-aleatório, foram também excluídas aquelas que apresentaram patrimônio líquido e lucro operacional ajustado (EBITDA) com valor negativo, visto que isso distorce os resultados da metodologia de análise aplicada neste estudo.

Ao final desses ajustes, obteve-se uma amostra composta por 33 empresas que operaram em 2001 e 2002, com um volume de vendas de $\mathrm{R} \$ 28,917$ bilhões, que representa aproximadamente $32 \%$ dos $\mathrm{R} \$ 90,497$ bilhões faturados pelo setor em 2002 (IBGE, 2005). Da amostra, 
foram tabulados os dados de Ativo Total (AT), Patrimônio Líquido (PL), Receita Operacional Líquida (ROL), (EBITDA - Earnings Before Interest, Taxes, Depreciation and Amortization - Retorno Operacional Antes dos Juros, Impostos, Depreciação e Amortização), Lucro Líquido (LL) e Liquidez Corrente (LC). Convém salientar que, em função das aquisições e fusões, as operações da Braskem estavam distribuídas entre a COPENE, Nitrocarbono e OPP Química, razão pela qual a amostra alcançou 35 empresas em 2001.

\subsection{Metodologia de cálculo do valor econô- mico criado}

Neste trabalho, partiu-se da premissa de que os valores publicados das contas patrimoniais agregadas e de resultados estão em consonância com as requisições básicas para o cálculo do lucro econômico e, por conseqüência, do valor econômico criado.

Portanto, o cálculo do lucro econômico será operacionalizado aplicando-se a Equação 2.

O cálculo do custo médio ponderado de capital (CMPC) levou em consideração as seguintes abordagens: i) como custo do capital de terceiros (CCT), foi utilizada a taxa explícita obtida pela relação entre as despesas financeiras e os passivos onerosos das empresas analisadas; e ii) como custo do capital próprio $(C C P)$, é necessária a adoção de uma série de aproximações, visto que os acionistas ou proprietários das empresas não demandam um retorno explícito para seu capital. No entanto, há uma orientação básica para se calcular o $C C P$, já que o conceito do custo de oportunidade do capital permeia toda a análise de investimentos. Isto é, um investidor somente empregará capital numa empresa, caso ela lhe proporcione um rendimento superior àquele que poderia ser obtido pela aplicação em outra empresa ou em outra modalidade de investimento, em condições de risco similares.

Neste trabalho, o cálculo do custo do capital próprio foi operacionalizado conforme a proposição de Damodaran (1999), que é baseada no modelo de precificação de ativos de capital (Capital Asset Pricing Model $-C A P M)$.

O CAPM parte do pressuposto de que os investidores demandam uma remuneração básica para seus investimentos, caracterizada pela aplicação em um ativo livre de risco, mais um prêmio pelo risco adicional de estar investindo na empresa em análise, que pode ser assim formalizado:

$$
i_{C C P}=R_{f}+\beta_{i}\left(R_{m}-R_{f}\right)+\lambda
$$

em que: $\mathrm{i}_{\text {CCP }}$ é a taxa do custo do capital próprio; $R_{f}$ refere-se à taxa de remuneração do ativo livre de risco; $\beta_{i}$ é o beta alavancado da empresa analisada $\mathrm{i} ; R_{m}$ refere-se ao prêmio de risco do mercado acionário; e $\lambda$ trata do fator do risco-país.
A inclusão do fator do risco-país deve-se ao fato de que, como não se dispõe de dados para a composição dos valores de $R_{f}, \beta_{i}$ e $R_{m}$ para o setor químico e petroquímico nacional, foram utilizados os dados do mercado americano, adaptados ao mercado brasileiro pela inclusão de $\lambda$ e por outros ajustes que serão detalhados na seqüência.

São considerados ativos livres de risco $\left(R_{f}\right)$ os títulos da dívida pública de países que não apresentam risco de inadimplência e nem incerteza a respeito das taxas de reinvestimento. Em países emergentes, que é o caso do Brasil, não há aplicações realmente livres de risco, nem mesmo em títulos públicos. Por essa razão, adotou-se como pro$x y$ as taxas de remuneração média dos bônus do governo norte-americano de longo prazo, que se encontram na base de dados disponibilizada por Damodaran (2005). A mesma base de dados ofereceu os valores dos prêmios de risco de mercado acionário $R_{m}$, que tratam da diferença entre o retorno esperado do mercado acionário e a taxa de retorno livre de risco, e do fator do risco-país $\lambda$, sintetizado pelo spread-over-treasury dos títulos da dívida externa brasileira.

Para o cálculo de $\beta_{i}$ foi utilizado o beta não-alavancado $\beta_{n a}$ do setor de química básica americano, que também está disponível na base de dados de Damodaran (2005). O cálculo de $\beta_{i}$ para cada empresa do setor brasileiro requereu a seguinte equação de ajuste:

$$
\beta_{i}=\beta_{n a}\left\{1+\left[(1-T)\left(\frac{D}{P L}\right)\right]\right\}
$$

em que $\mathrm{T}$ equivale à alíquota do imposto de renda e da contribuição social sobre o lucro e D refere-se ao passivo oneroso da empresa. Essa adaptação torna mais realista a análise, pois, quanto maior o grau de alavancagem financeira da empresa, maior será seu risco, efeito que estará incorporado ao seu beta alavancado $\beta_{i}$.

\section{Análise empírica}

Os resultados do cálculo do valor econômico criado das empresas do setor químico e petroquímico para os anos 2001 e 2002 encontram-se na Tabela 1, juntamente com suas respectivas participações relativas no mercado (vide gráficos de dispersão na Figura 1), que foram calculadas conforme a proposta de Hax e Majluf (Em Dyson, 1990, p. 54), pela qual as vendas da empresa $i$ são comparadas com as vendas do competidor líder $L$, ou $p r^{\mathrm{i}}=R O L^{\mathrm{i}} / R O L^{\mathrm{L}}$.

A análise dos dados mostrou que o ano de 2001 foi de desempenho ruim para praticamente todo o setor, pois, da amostra de 35 empresas, somente a Triunfo e a UNIPAR criaram valor. As demais 33 empresas destruíram valor, pois apresentaram o valor econômico negativo. De um modo geral, o fato de uma empresa deter maior ou menor participação no mercado não a afastou e nem a aproximou da destruição de valor. 
Tabela 1. Criação e destruição de valor no setor químico e petroquímico.

\begin{tabular}{|c|c|c|c|c|c|}
\hline \multirow[t]{2}{*}{ Nr. } & \multirow[t]{2}{*}{ Empresa } & \multicolumn{2}{|l|}{2002} & \multicolumn{2}{|c|}{2001} \\
\hline & & LE (R\$ Milhões) & prm & LE (R\$ Milhões) & prm \\
\hline 1 & Aga & $-34,37$ & 0,070 & $-4,00$ & 0,068 \\
\hline 2 & Basf & - 299,90 & 0,729 & $-33,13$ & 0,798 \\
\hline 3 & Bayer & $-93,56$ & 0,331 & $-13,49$ & 0,434 \\
\hline 4 & Braskem & $-1.138,41$ & 1,000 & - & - \\
\hline 5 & Bunge & $-93,99$ & 0,819 & $-25,37$ & 0,682 \\
\hline 6 & Carbocloro & 73,04 & 0,100 & $-18,09$ & 0,115 \\
\hline 7 & Ciquine & $-70,70$ & 0,074 & $-0,35$ & 0,067 \\
\hline 8 & Clariant & 23,62 & 0,277 & $-9,92$ & 0,253 \\
\hline 9 & Copesul & $-109,88$ & 0,796 & $-41,94$ & 0,752 \\
\hline 10 & Deten & 68,52 & 0,119 & $-10,20$ & 0,121 \\
\hline 11 & Fertibrás & $-24,56$ & 0,085 & $-0,55$ & 0,079 \\
\hline 12 & Fosfértil & 200,02 & 0,173 & $-18,42$ & 0,153 \\
\hline 13 & Isopol & $-14,67$ & 0,073 & $-0,91$ & 0,074 \\
\hline 14 & Milena & $-58,82$ & 0,168 & $-13,94$ & 0,190 \\
\hline 15 & Millennium & 17,66 & 0,082 & $-6,91$ & 0,082 \\
\hline 16 & Monsanto & 63,69 & 0,182 & $-4,32$ & 0,027 \\
\hline 17 & Natura & 10,95 & 0,288 & $-16,49$ & 0,274 \\
\hline 18 & NitroQuímica & 62,16 & 0,059 & $-1,92$ & 0,060 \\
\hline 19 & Oxiteno & 120,63 & 0,090 & $-1,24$ & 0,089 \\
\hline 20 & OxitenoNE & 47,81 & 0,182 & $-14,73$ & 0,182 \\
\hline 21 & Petroflex & 13,80 & 0,223 & $-10,07$ & 0,207 \\
\hline 22 & Petr.União & $-51,56$ & 0,390 & $-20,96$ & 0,461 \\
\hline 23 & Polialden & $-5,59$ & 0,067 & $-1,07$ & 0,081 \\
\hline 24 & Polibrasil & $-12,84$ & 0,245 & $-7,29$ & 0,219 \\
\hline 25 & Pol.União & $-16,31$ & 0,066 & $-1,40$ & 0,071 \\
\hline 26 & Politeno & 0,55 & 0,201 & $-8,54$ & 0,207 \\
\hline 27 & RennerS & 2,91 & 0,096 & $-1,99$ & 0,099 \\
\hline 28 & Solvay & $-10,38$ & 0,152 & $-9,20$ & 0,158 \\
\hline 29 & Trevo & 29,07 & 0,195 & $-4,16$ & 0,170 \\
\hline 30 & Trikem & $-512,22$ & 0,311 & $-42,37$ & 0,314 \\
\hline 31 & Triunfo & 6,03 & 0,081 & 1,59 & 0,092 \\
\hline 32 & Ultrafertil & 96,68 & 0,229 & $-24,45$ & 0,221 \\
\hline 33 & Unipar & 26,73 & 0,037 & 2,50 & 0,031 \\
\hline 33 & *COPENE & - & - & $-1,1$ & 1,000 \\
\hline 34 & *Nitrocarbono & - & - & $-56,3$ & 0,066 \\
\hline 35 & *OPP Química & - & - & $-220,4$ & 0,561 \\
\hline
\end{tabular}

*A Braskem foi formada em 2002, com a fusão das empresas COPENE, Nitrocarbono e OPP Química, que apresentaram os seguintes dados em 2001.
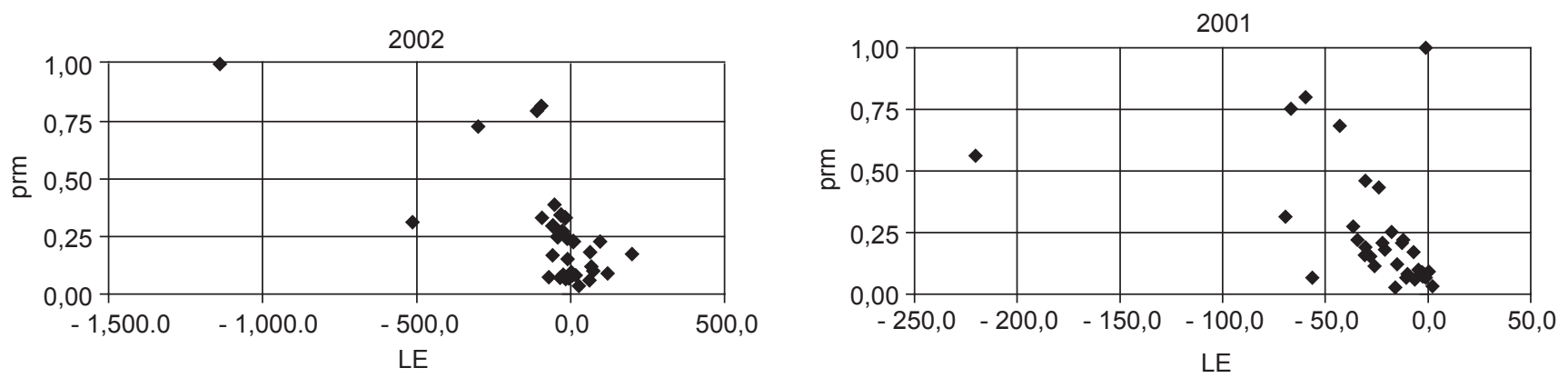

Figura 1. Gráficos de dispersão: criação e destruição de valor e participação no mercado. 
Em 2002, houve uma melhora no desempenho do setor, pois pouco mais da metade das empresas (17) criaram valor (Carbocloro, Clariant, Deten, Fosfértil, Millennium, Monsanto, Natura, Nitroquímica, Oxiteno, OxitenoNE, Petroflex, Politeno, RennerS, Trevo, Triunfo, Ultrafértil e Unipar), enquanto que as demais 16 empresas destruíram valor, em média, com maior magnitude do que em 2001. O segundo grupo inclui a empresa líder Braskem, que consolida as operações da COPENE, Nitrocarbono e OPP Química. Esse comportamento negativo do valor da Braskem era previsto, principalmente, pelo ajuste que as aquisições operaram em sua estrutura financeira. No entanto, projeta-se que os efeitos sinergísticos do processo surtam efeitos positivos em sua rentabilidade e valor a longo prazo.

Com o objetivo de analisar o grau de eficiência da gestão operacional das empresas analisadas e para validar a hipótese de que variáveis de desempenho operacional e de estrutura de capital condicionam a criação de valor, optou-se pela aplicação de uma análise de regressão. Para tanto, foi especificado o seguinte grupo básico de variáveis de desempenho para teste da hipótese central:

- Giro do ativo $\left(g_{i}\right)$, que expressa o volume de negócios gerado pelos investimentos (ativos) totais da empresa, calculado por $g a_{i}=R O L / A T_{i}$;

- Rentabilidade operacional do ativo $\left(\right.$ roa $\left._{i}\right)$, que mede a lucratividade operacional gerada pelos investimentos (ativos) totais da empresa, calculada por roa $_{i}=$ EBITDA $/ A T_{i}$, em que EBITDA corresponde ao lucro operacional ajustado ao regime de caixa. Essa é a principal medida de desempenho gerencial, pois compara a habilidade dos gestores de operações em gerar lucro operacional com relação aos ativos que estão sob seu controle (Brigham et al., 1999); e

- Endividamento $\left(e n d_{i}\right)$, que mede a participação dos capitais de terceiros em relação ao capital próprio empregado na empresa, calculado por end $_{i}=P C_{i}+P E L P{ }_{i}$ $P L_{i}$, em que $P E L P$ refere-se ao passivo exigível a longo prazo.

Como se está partindo do pressuposto de que as variáveis $g a_{i}, r o a_{i}$ e $e n d_{i}$ condicionam a criação ou destruição de valor em uma companhia, tem-se a seguinte relação:

$$
c v=f\left(g a_{i}, \text { roa }_{i}, \text { end }_{i}\right)
$$

em que $c v$ é a condição do valor, que é a situação de criação ou destruição, assim formalizada:

$$
c v=\left\{\begin{array}{l}
1 \text { sse } L E>0 \\
0 \text { sse } L E \leq 0
\end{array}\right.
$$

Como $c v$ é uma variável dependente dicotômica (Tabela 2), isto é, somente pode assumir o valor 1 ou 0 , assumindo 1 quando a empresa criou valor e 0 quando a em- presa destruiu valor. A análise requer o uso de ferramentas estatísticas apropriadas para a regressão dos dados.

Das ferramentas disponíveis para análise nas situações em que a variável dependente é dummy, isto é, está limitada aos valores 1 ou 0 , optou-se pelo uso da regressão logística binária. O modelo logit tem apresentado boa aderência a problemas de análise econômica (Gujarati, 1995) e toma a seguinte forma:

$$
P_{i}=E\left(Y=1 \mid X_{i}\right)=\frac{1}{1+e^{-\left(\beta_{1}+\beta_{2} 2\right.}}
$$

A adaptação de (7) ao problema tratado neste artigo, pode ser assim especificada:

$$
P_{i}=E\left(Y=1 \mid X_{i}\right)=\frac{1}{1+e^{-\left(\beta_{1}+\beta_{2} 8 q_{1}+\beta_{3} r o a_{4}+\beta_{4} e n d_{i}\right.}}
$$

A variável $P_{i}$ retorna a probabilidade de a empresa i criar valor, de acordo com seus resultados operacionais, giro do ativo e estrutura de capitais (grau de endividamento). A estimação dos parâmetros $\beta_{1}$ a $\beta_{4}$ é feita por máxima verossimilhança, tendo sido utilizado o pacote estatístico SPSS (Statistical Package for the Social Sciences) 10.0 para processamento dos cálculos, os resultados são apresentados na Tabela 3 .

A turbulência do desempenho do setor químico e petroquímico em 2001 foi captada pelo modelo e a análise estatística não validou a hipótese central do trabalho, pois nenhuma variável explicativa apresentou significância em relação à variável dependente. Ou seja, em 2001 não houve significância estatística entre a criação de valor e as variáveis autônomas consideradas. A estimativa encerrou na quinta iteração, porque as estimativas dos parâmetros mudaram para menos de 0,001 .

Com relação ao ano 2002, os resultados refletiram a grande mudança no perfil competitivo do setor, que se tornou mais concentrado e que demandará a adoção de estratégias de operações adequadas a essa nova realidade. A análise dos dados mostrou que as variáveis significativas do modelo, o retorno operacional sobre o ativo $\left(\right.$ roa $\left._{i}\right)$ e o endividamento $\left(\right.$ end $_{i}$ ), comprovaram os movimentos previsíveis e validaram a hipótese central deste trabalho. $\mathrm{O}$ teste do modelo completo apresentou um - 2LL de 29,085 e as estatísticas Cox e Snell $\mathrm{R}^{2}$ e Nagelkerke $\mathrm{R}^{2}$, que são semelhantes ao R2 do modelo de regressão múltipla, apresentaram os resultados 0,396 e 0,528, respectivamente. Ou seja, tomando-se o coeficiente de Nagelkerke, pode-se inferir que $52,8 \%$ da variação na criação de valor nas empresas analisadas pode ser explicada pelo modelo de regressão logística.

O coeficiente do retorno operacional sobre os ativos $\left(r o a_{i}\right)$ é positivo e guarda uma alta relação com a probabilidade de se criar valor, isto é, pequenas variações positivas no EBITDA geram um grande aumento na pro- 
Tabela 2. Variáveis de gestão de resultados do setor químico e petroquímico.

\begin{tabular}{|c|c|c|c|c|c|c|c|c|c|}
\hline \multirow[t]{2}{*}{ Nr. } & \multirow{2}{*}{ Empresa } & \multicolumn{4}{|c|}{2002} & \multicolumn{4}{|c|}{2001} \\
\hline & & cv & ga & roa & end & cv & ga & roa & end \\
\hline 1 & Aga & 0 & 0,773 & 0,095 & 1,617 & 0 & 0,800 & 0,187 & 4,585 \\
\hline 2 & Basf & 0 & 0,886 & 0,128 & 2,792 & 0 & 0,954 & 0,109 & 2,784 \\
\hline 3 & Bayer & 0 & 1,408 & 0,051 & 2,270 & 0 & 1,233 & 0,115 & 2,339 \\
\hline 4 & Braskem & 0 & 0,340 & 0,049 & 4,649 & - & - & - & - \\
\hline 5 & Bunge & 0 & 1,072 & 0,062 & 2,149 & 0 & 1,121 & 0,118 & 2,144 \\
\hline 6 & Carbocloro & 1 & 1,286 & 0,574 & 0,677 & 0 & 1,388 & 0,659 & 0,649 \\
\hline 7 & Ciquine & 0 & 1,378 & 0,156 & 5,077 & 0 & 1,167 & 0,074 & 0,818 \\
\hline 8 & Clariant & 1 & 1,734 & 0,254 & 2,030 & 0 & 1,722 & 0,235 & 1,888 \\
\hline 9 & Copesul & 0 & 0,818 & 0,136 & 2,498 & 0 & 0,968 & 0,151 & 1,654 \\
\hline 10 & Deten & 1 & 1,140 & 0,344 & 1,086 & 0 & 1,313 & 0,364 & 0,697 \\
\hline 11 & Fertibrás & 0 & 0,959 & 0,072 & 2,387 & 0 & 1,006 & 0,059 & 1,726 \\
\hline 12 & Fosfértil & 1 & 0,450 & 0,192 & 1,510 & 0 & 0,422 & 0,152 & 1,098 \\
\hline 13 & Isopol & 0 & 1,395 & 0,134 & 0,246 & 0 & 1,191 & 0,155 & 0,297 \\
\hline 14 & Milena & 0 & 0,703 & 0,182 & 5,592 & 0 & 0,722 & 0,151 & 4,647 \\
\hline 15 & Millennium & 1 & 0,655 & 0,235 & 0,427 & 0 & 0,713 & 0,202 & 0,389 \\
\hline 16 & Monsanto & 1 & 0,708 & 0,315 & 4,582 & 0 & 0,117 & 0,050 & 13,488 \\
\hline 17 & Natura & 1 & 1,777 & 0,288 & 5,405 & 0 & 1,864 & 0,313 & 4,909 \\
\hline 18 & NitroQuímica & 1 & 0,260 & 0,055 & 3,764 & 0 & 0,297 & 0,042 & 6,173 \\
\hline 19 & Oxiteno & 1 & 0,359 & 0,070 & 0,417 & 0 & 0,332 & 0,054 & 0,184 \\
\hline 20 & OxitenoNE & 1 & 0,915 & 0,267 & 0,754 & 0 & 0,999 & 0,255 & 0,545 \\
\hline 21 & Petroflex & 1 & 1,083 & 0,170 & 4,103 & 0 & 1,125 & 0,160 & 4,697 \\
\hline 22 & Petr.União & 0 & 1,033 & 0,072 & 1,583 & 0 & 1,303 & 0,170 & 0,809 \\
\hline 23 & Polialden & 0 & 0,460 & 0,029 & 0,379 & 0 & 0,517 & 0,049 & 0,376 \\
\hline 24 & Polibrasil & 0 & 0,801 & 0,073 & 1,893 & 0 & 1,055 & 0,127 & 1,141 \\
\hline 25 & Pol.União & 0 & 0,918 & 0,107 & 0,481 & 0 & 0,907 & 0,110 & 0,429 \\
\hline 26 & Politeno & 1 & 1,293 & 0,181 & 0,289 & 0 & 1,347 & 0,230 & 0,234 \\
\hline 27 & RennerS & 1 & 1,363 & 0,154 & 3,607 & 0 & 1,562 & 0,128 & 3,353 \\
\hline 28 & Solvay & 0 & 1,952 & 0,319 & 17,822 & 0 & 1,673 & 0,254 & 11,919 \\
\hline 29 & Trevo & 1 & 1,931 & 0,144 & 1,461 & 0 & 2,104 & 0,195 & 1,181 \\
\hline 30 & Trikem & 0 & 0,460 & 0,111 & 7,528 & 0 & 0,444 & 0,166 & 1,932 \\
\hline 31 & Triunfo & 1 & 1,667 & 0,108 & 0,273 & 1 & 1,833 & 0,218 & 0,275 \\
\hline 32 & Ultrafertil & 1 & 0,801 & 0,270 & 0,687 & 0 & 0,958 & 0,314 & 0,491 \\
\hline 33 & Unipar & 1 & 0,147 & 0,014 & 0,214 & 1 & 0,119 & 0,009 & 0,231 \\
\hline 34 & COPENE & - & - & - & - & 0 & 0,576 & 0,090 & 1,525 \\
\hline 35 & Nitrocarbono & - & - & - & - & 0 & 0,706 & 0,028 & 2,358 \\
\hline 36 & OPP Química & - & - & - & - & 0 & 0,548 & 0,088 & 5,870 \\
\hline
\end{tabular}

Tabela 3. Resumo dos Testes Estatísticos.

\begin{tabular}{ccc}
\hline Variáveis & $\mathbf{2 0 0 2}$ & $\mathbf{2 0 0 1}$ \\
\hline Constante & $-1,034$ & 71,567 \\
& $(0,3820)$ & $(0,961)$ \\
\hline$g a_{i}$ & $-0,9380$ & 278,031 \\
& $(0,4260)$ & $(0,962)$ \\
\hline roa & 24,5550 & $-2196,851$ \\
& $(0,0170)^{*}$ & $(0,961)$ \\
\hline end & $-0,5360$ & $-317,710$ \\
& $(0,0590)^{* *}$ & $(0,961)$ \\
\hline
\end{tabular}

* Significância a $5 \%$.

** Significância a $10 \%$. babilidade de criação de valor. Isto é compreensível, pois o EBITDA sintetiza todo o esforço do corpo gestor pela eficiência da organização em suas áreas funcionais de produção, recursos humanos, vendas e marketing.

O grau de endividamento $\left(e n d_{i}\right)$ tem seu coeficiente negativo, pois seu aumento reduz a probabilidade de criação de valor à empresa. Como a maioria das empresas do setor está altamente endividada, esse comportamento pode ser explicado pelo fato de, a maior parte das empresas do setor econômico analisado, ter ultrapassado o ponto ótimo de sua estrutura de capitais, o que faz com 
que os efeitos da alavancagem financeira sejam sentidos no sentido oposto, isto é, de potencialização de seus prejuízos. Nesse caso, o aumento do endividamento gera um aumento nas despesas financeiras, o que move o ponto de equilíbrio para a direita e a empresa precisará aumentar suas vendas para gerar mais caixa, visando cobrir seus débitos adicionais, necessários ao financiamento de sua estrutura de capitais debilitada. Isso faz com que essas empresas tenham um risco significativo, pois estão muito vulneráveis aos problemas de mercado. As possibilidades de quedas nas vendas podem aumentar a exposição da empresa à insolvência, que é uma situação comum às empresas de alto grau de alavancagem financeira.

Em relação ao coeficiente da variável giro do ativo $\left(g a_{i}\right)$, a priori, o modelo mostrou uma relação inversa na probabilidade da empresa criar valor, isto é, quanto maior o volume de vendas gerado pelos ativos da empresa, menor a probabilidade de criação de valor. Embora essa variável não tenha sido significativa no modelo, ela apresenta uma importante questão para reflexão, visto que investigações mais profundas podem ser feitas para identificar as causas desse comportamento. É possível que os custos variáveis dessas empresas representem um alto grau no custo total, ou que as empresas tenham ultrapassado o ponto ótimo de seu nível de economias de escala, ou, ainda, pode ter ocorrido uma conjugação de ambos.

Como a hipótese central do trabalho foi validada em 2002, a equação de regressão logística ajustada pode ser uma ferramenta útil de apoio ao processo de planejamento estratégico das operações da companhia. Embora sintetize a movimentação das variáveis de todas as empresas do setor, os resultados de sua simulação podem indicar direções e possíveis desdobramentos das estratégias previstas. Além disso, a simulação permite a identificação do limiar de responsabilidade atribuída ao gestor de operações na criação e destruição de valor em uma companhia, pois fornece uma medida numérica dos efeitos de variações nos indicadores de desempenho na probabilidade de se criar valor.

Como exemplo, tome-se a Tabela 4, que considera as simulações da equação ajustada (9), que inclui todas as variáveis. Mesmo que o giro do ativo não tenha sido estatisticamente significativo, ele pode ser considerado no modelo de simulação, o que caracteriza uma posição mais conservadora, pois um maior número de variáveis estará interagindo e influenciando a probabilidade de criação de valor.

$$
P_{i}=E\left(Y=1 \mid X_{i}\right)=\frac{1}{1+e^{-\left(-1,034-0,938 a_{4}+24,55 \text { rroa }_{i}-0,536 \text { end }_{i}\right)}}
$$

As simulações tomam por base a primeira linha de dados, que supostamente podem ser os indicadores de resultados mais recentes da organização. A simulação 1 mostra que, mantendo-se constantes o giro do ativo e o endividamento, uma variação de $100 \%$ no retorno operacional ocasiona um aumento na probabilidade de se criar valor de $56,69 \%$ para $93,85 \%$.

Na simulação 2, verifica-se que um aumento de $20 \%$ no giro do ativo, acompanhado de um aumento de $150 \%$ no retorno operacional, mantendo-se o endividamento constante, ocasiona um aumento de $47,34 \%$ para $97,74 \%$ na probabilidade de se criar valor.

Na simulação 3, tem-se o cenário de que a empresa terá apenas 36,94\% de probabilidade de criar valor, o que significa que ela estará mais próxima de destruí-lo, no caso da administração de operações não obtiver um aumento na rentabilidade operacional ao mesmo tempo em que o giro dos ativos aumentar $80 \%$ e o endividamento crescer $25 \%$.

A simulação 4 apresenta um cenário favorável, pelo qual a probabilidade de criação de valor chega a 96,45\%, caso a administração de operações viabilize um aumento de $200 \%$ no resultado operacional, enquanto que o giro do ativo e o endividamento reduzem-se em $50 \%$.

No caso das simulações considerarem somente as variáveis significativas do modelo (10), a análise se torna mais simplista e menos realista, por considerar apenas a influência do retorno operacional e do endividamento na probabilidade de criação de valor, conforme os dados da Tabela 5.

$$
P_{i}=E\left(Y=1 \mid X_{i}\right)=\frac{1}{1+e^{-\left(-1,034+24,55 \text { roo }_{i}-0,5360 \text { end }\right)}}
$$

O uso das simulações pode levar a empresa a uma maior aproximação com a realidade das demais concorrentes do setor, que no caso químico e petroquímico ainda se encontra em fase de transição para um novo modelo de gestão, o que deve ser acompanhado de perto pelos gestores de operações.

Tabela 4. Simulações da equação de regressão completa (Equação 9).

\begin{tabular}{cccccccc}
\hline Simulação & $\boldsymbol{g} \boldsymbol{a}_{\boldsymbol{i}}$ & $\boldsymbol{\Delta} \boldsymbol{\%}$ & $\boldsymbol{r o a}_{\boldsymbol{i}}$ & $\Delta \boldsymbol{\%}$ & $\boldsymbol{e n d}_{\boldsymbol{i}}$ & $\Delta \boldsymbol{\%}$ & $\boldsymbol{P}_{\boldsymbol{i}}=\boldsymbol{E}(\boldsymbol{Y}=\boldsymbol{1} \mid \boldsymbol{X})$ \\
\hline Base & 1,0000 & - & 0,1000 & - & 0,4000 & - & 0,5669 \\
1 & 1,0000 & 0 & 0,2000 & $100 \%$ & 0,4000 & 0 & 0,9385 \\
2 & 1,2000 & $20 \%$ & 0,2500 & $150 \%$ & 0,4000 & 0 & 0,9774 \\
3 & 1,8000 & $80 \%$ & 0,1000 & 0 & 0,5000 & $25 \%$ & 0,3694 \\
4 & 0,5000 & $-50 \%$ & 0,2000 & $200 \%$ & 0,2000 & $-50 \%$ & 0,9645 \\
\hline
\end{tabular}


Tabela 5. Simulações da equação de regressão reduzida (Equação 10).

\begin{tabular}{cccccc}
\hline Simulação & $\boldsymbol{r o a}_{\boldsymbol{i}}$ & $\Delta \%$ & $\boldsymbol{e n d}_{\boldsymbol{i}}$ & $\Delta \%$ & $\boldsymbol{P}_{\boldsymbol{i}}=\boldsymbol{E}(\boldsymbol{Y}=\boldsymbol{1} \mid \boldsymbol{X})$ \\
\hline Base & 0,1000 & - & 0,4000 & 0 & 0,7698 \\
1 & 0,2000 & $100 \%$ & 0,4000 & 0 & 0,9750 \\
2 & 0,2500 & $150 \%$ & 0,4000 & 0,5000 & 0,9925 \\
3 & 0,1000 & 0 & 0,2000 & $-50 \%$ & 0,7601 \\
4 & 0,2000 & $200 \%$ & & 0,9775 \\
\hline
\end{tabular}

\section{Conclusões}

Este trabalho enalteceu aos gestores a importância de se monitorar a criação de valor na empresa e no próprio setor de atuação, como forma de avaliar o alcance de sua estratégia de operações, que dá suporte aos sistemas de avaliação multidimensional, notadamente àqueles do tipo Balanced Scorecard.

O estudo apresentou indícios de que a responsabilidade do gestor de operações com a criação ou destruição de valor em uma organização é significativa, pois a hipótese central do trabalho foi, a priori, validada. Os índices econômico-financeiros operacionais, conjugados com indicadores de produtividade de ativos e endividamento, explicaram a criação ou destruição de valor no setor químico e petroquímico brasileiro em 2002, sendo que o coeficiente do retorno operacional sobre os ativos $\left(\right.$ roa $\left._{i}\right)$, que é a principal medida de desempenho do gestor de operações, é positivo e guarda uma alta relação com a probabilidade de se criar valor. Os resultados alcançados podem orientar o estabelecimento dos limiares da responsabilidade do gestor de operações com a criação e destruição de valor, na definição das métricas para avaliação do alcance da estratégia de operações.

Embora o modelo tenha sido validado para o ano de 2002, algumas questões precisam ser aprofundadas em estudos posteriores. A primeira delas diz respeito à dúvida em relação aos dados de 2001, que não apresentaram significância estatística, embora no ano seguinte isso tenha ocorrido. A segunda delas evidencia a necessidade de se estender o estudo a outros segmentos econômicos, visando identificar se o coeficiente negativo do índice de endividamento é também identificado em setores altamente endividados e se isso, realmente, é resultado de ter sido ultrapassado o ponto ótimo da estrutura de capitais das empresas. A mesma extensão dos estudos deve ser feita com relação à terceira questão instigante, que diz respeito ao coeficiente da variável giro do ativo $\left(g a_{i}\right)$, que mostrou uma relação inversa na probabilidade da empresa criar valor. Isso seria uma função da estrutura de custos operacionais da empresa ou de sua própria estrutura de capitais, ou de ambas?

Em que pesem as limitações da metodologia apresentada, este trabalho mostra que o setor químico e petroquímico brasileiro está avançando em suas reformas, visando o aumento de sua produtividade e criação de valor. A onda de fusões e aquisições no setor tem mostrado que as indústrias estão dispostas a aumentar seu domínio de mercado, ultrapassando suas preocupações com a capacidade de oferta e considerando os demais elos de sua cadeia produtiva, especialmente seus fornecedores de insumos. Essa é uma forma de atuar na redução dos custos operacionais e na qualidade de seus insumos, o que afetará seus processos, produtos e valor.

Por fim, além de apresentar ao gestor de operações uma ferramenta para avaliação e monitoramento da criação de valor em sua companhia, bem como de simulação empresarial, este trabalho procurou confrontá-lo com a necessidade de ampliar o foco da análise, expandido-a para todo o setor de atuação. Espera-se que o gestor de operações expanda rapidamente a aplicação desta metodologia de análise para os demais elos da cadeia produtiva e econômica em que sua organização está inserida. 


\title{
Referências Bibliográficas
}

AHMED, N. U., MONTAGNO, R. V. Operations strategy and organizational performance: an empirical study. International Journal of Operations \& Production Management, v. 16, n. 5, p. 41-53, 1996.

BRIGHAM, E. F., GAPENSKI, L. C., EHRHARDT, M. C Financial Management: Theory and Practice. $9^{\text {th }}$ ed. Orlando, Florida: Dryden Press, 1999.

COPELAND, T., KOLLER, T., MURRIN, J. Valuation: Measuring and Managing the Value of Companies. 2. ed. New York: John Wiley \& Sons, Inc., 1995.

DAMODARAN, A. Corporate Finance: The Data Page. Disponível em: <http://pages.stern.nyu.edu/ adamodar/>. Acesso em: mar. 2005.

DAMODARAN, A. Applied Corporate Finance: A User's Manual. New York: John Wiley \& Sons, 1999.

HAX, A., MAJLUF, N. The Use of Growth-Share Matrix in Strategic Planning. In DYSON, R. G. Strategic Planning: Models and Analytical Techniques. London: John Wiley \& Sons, p. 51-72, 1990.

FGV - Fundação Getúlio Vargas. FGV Dados. Disponível em: <http://www2.fgv.br/dgd/asp/dsp/FGVDADOS. asp>. Acesso em: fev. 2005.

GUJARATI, D. N. Basic Econometrics. New York: McGraw-Hill, Inc., 1995.

IBGE - Instituto Brasileiro de Geografia e Estatística. Pesquisa Industrial Anual - PIA Produto. Disponível em: <http://www.ibge.gov.br>. Acesso em: mar. 2005.

KAPLAN, R. S., NORTON, D. P. Using the Balanced Scorecard: Translating Strategy into Action. Boston, Harvard Business School Press, 1996.

LOWSON, R. H. Retail operational strategies in complex supply chains. International Journal of Logistics Management, v. 12, n. 1, 2001, p. 97-111.

LOWSON, R. H. Operations strategy: genealogy, classification and anatomy. International Journal of Operations \& Production Management, v. 22, n. 10, p. 1112-1129, 2002.

MARSHALL, Alfred. Principles of Economics. v. 1, New York: MacMillan \& Co., 1890.

PORTER, M. E. What is strategy? Harvard Business Review, November/December, p. 61-81, 1996.

\section{VALUE CREATION AND OPERATIONAL STRATEGY: A STUDY OF BRAZIL'S CHEMICAL AND PETROCHEMICAL SECTOR}

\begin{abstract}
This paper discusses the integration of operational strategies and corporate finance, focusing on the need for the operations manager to plan a strategy focusing on the creation of corporate value. A methodology is proposed for calculating the added economic value of Brazil's chemical and petrochemical industry in 2001 and 2002, a period marked by major changes in the sector's competitive profile. The results of 2002 validate the core hypothesis of this study, providing a simulation tool to identify the limits of the operations manager's responsibility in the creation of corporate value.
\end{abstract}

Keywords: operational strategies, creation of corporate values, Brazil's chemical and petrochemical sector, logistical regression, simulation of corporate value. 